\title{
Missed opportunities for HIV testing in people diagnosed with HIV, Estonia, 2014 to 2015
}

Kristi Rüütel ${ }^{1}$, Liis Lemsalu ${ }^{1}$, Sirly Lätt ${ }^{2}$, Jevgenia Epštein ${ }^{3}$, on behalf of OptTEST by HiE ${ }^{4}$

1. National Institute for Health Development, Tallinn, Estonia

2. Estonian Health Insurance Fund, Tallinn, Estonia

3. Estonian Health Board, Tallinn, Estonia

4. Optimising testing and linkage to care for HIV across Europe (http://www.opttest.eu/)

Correspondence: Kristi Rüütel (kristi.ruutel@tai.ee)

Citation style for this article:

Rüütel Kristi, Lemsalu Liis, Lätt Sirly, Epštein Jevgenia, on behalf of OptTEST by HiE. Missed opportunities for HIV testing in people diagnosed with HIV, Estonia, 2014 to 2015. Euro Surveill. 2019;24(15):pii=1800382. https://doi.org/10.2807/1560-7917.ES.2019.24.15.1800382

Background: Studies of missed opportunities for earlier diagnosis of HIV have shown that patients with undiagnosed HIV often present to healthcare settings numerous times before eventually receiving their diagnosis. Aim: The aim of the study was to assess missed opportunities for HIV testing among people newly diagnosed with HIV. Methods: In this observational retrospective study, we collected data from the Estonian Health Board on new HIV cases in people aged 16-49 years diagnosed in 2014-15 and from the Estonian Health Insurance Fund database for treatment invoices on their contacts with healthcare services in the 2 years preceding diagnosis. Diagnoses on treatment invoices were categorised as HIV indicator conditions using ICD-10 codes. Results: Of 538 newly diagnosed HIV cases (62.5\%; 336 men), $82 \%$ had visited healthcare services at least once during the 2 years before HIV diagnosis; the mean number of visits was 9.1. Of these, $16 \%$ had been tested for HIV and $31 \%$ had at least one ICD-10 code for an HIV indicator condition on at least one of their treatment invoices. In 390 cases of HIV indicator conditions, only $5 \%$ were tested for HIV. Of all new HIV cases aged 20-49 years from high-incidence regions (defined as priority groups in national testing guidance), $18 \%$ had been tested. Conclusions:The HIV testing rate in the 2 years before an HIV diagnosis was very low, even in the presence of an HIV indicator condition. This emphasises the importance of implementing the Estonian HIV testing guidelines.

\section{Introduction}

HIV testing is the gateway to HIV prevention, treatment, care and other support services [1]. Despite the widely acknowledged benefits of HIV testing, gaps remain in reducing the number of people living with HIV (PLHIV) who are unaware of their infection. Recent studies have suggested that the estimated proportion of PLHIV in the European Union (EU) and European Economic Area (EEA) who are undiagnosed is around $15 \%[2,3]$ and the average time between HIV infection and diagnosis is nearly 4 years [3]. EU countries are nearing the UNAIDS 90-90-90 target for the year 2020 and reducing the proportion of undiagnosed PLHIV remains the greatest barrier to achieving its target, suggesting that further efforts are needed to improve HIV testing rates [2].

Studies of missed opportunities for earlier diagnosis have shown that patients with undiagnosed HIV often present to healthcare settings numerous times before eventually receiving their diagnosis [4-6]. Many of them are not tested for HIV even if presenting with HIV indicator conditions (IC) [5,7]. HIV ICS are conditions which are AIDS-defining among PLHIV, conditions associated with an undiagnosed HIV prevalence of $>0.1 \%$, or conditions where not identifying the presence of HIV infection may have significant adverse implications for the individual's clinical management [8].

Estonia, located in north-eastern Europe, has a total population of ca 1.3 million [9] and one of the highest rates of newly diagnosed HIV cases in the EU (16.6 cases/100,000 population in 2017) [10]. Historically, the HIV epidemic has been concentrated among people who inject drugs, but heterosexual transmission and transmission among men who have sex with men (MSM) has increased in recent years [10]. In Estonia, HIV testing rates among the general population and people who inject drugs have been high. Approximately $12 \%$ of the total population is tested annually (119/1,000 population) [11]. Among people who inject drugs, up to $97 \%$ have tested for HIV during their lifetime, and up to $93 \%$ of those who are HIV-infected are aware of this [11]. Despite this, it is estimated that only $72 \%$ of PLHIV have been diagnosed [12]. Also, the proportion of concurrent AIDS has increased in recent years, from $2 \%$ in 2010 to $4 \%$ in 2017 , and most likely underestimated [13]. Data on $\mathrm{CD}_{4}$ counts is available only at the point of linkage to HIV care, not at diagnosis. This data also indicates a high proportion of late diagnosis: as 


\section{FIGURE}

Construction of the sampling frame, study to assess missed opportunities for HIV testing among newly diagnosed HIV cases, Estonia, 2014-2015

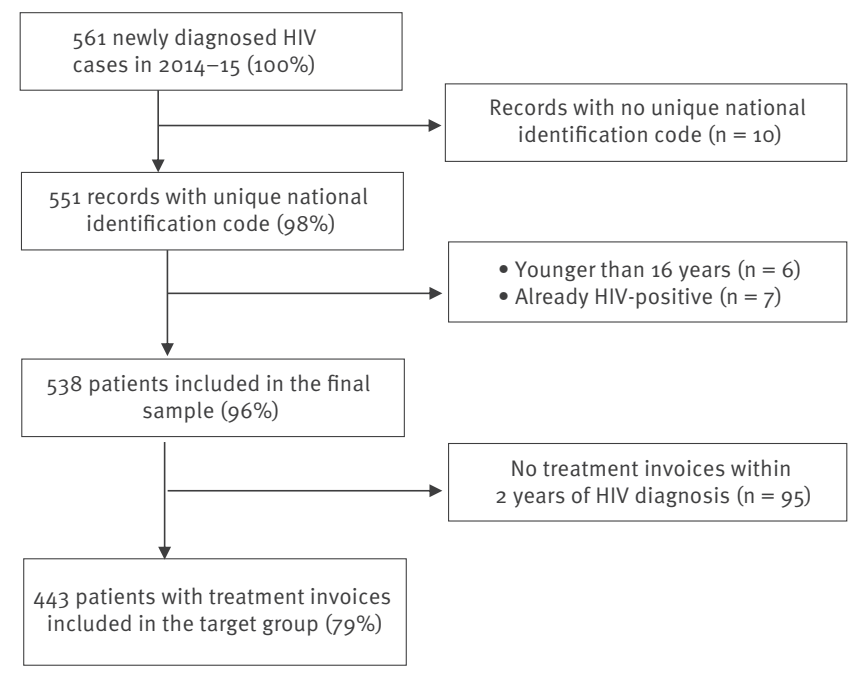

of $2013,53 \%$ of PLHIV first present to care with CD4 counts of fewer than 350 cells $/ \mathrm{ml}$ [14].

In Estonia, HIV testing has been available since 1987 and any doctor (whether a family practitioner or a specialist doctor) can recommend HIV testing based on clinical indications, risk assessment or the patient's request [11]. During the period studied, HIV testing was free of charge only for people with national health insurance. People with no insurance could test free of charge at anonymous testing sites, which are usually affiliated to local hospitals [15]. Testing is available at drug-treatment and harm-reduction sites. In prisons, HIV testing is offered routinely during imprisonment with high testing rates when entering prison $(97 \%$ in 2012) [16]. There are no special incentives for healthcare organisations to test. The latest national guidance for provider-initiated testing and counselling took effect in 2012. The main groups for whom HIV testing is recommended are people with HIV ICs, people who have injected drugs or had risky sex, pregnant women and prisoners. In the two regions with the highest HIV incidence (Harju County, including the capital, Tallinn, and Ida-Viru County in the north-east of the country), HIV testing is recommended for all people aged 16-49 years [17]. Previous research has identified large gaps in implementation of national testing guidance, including low testing rates in people with HIV ICs and in highincidence regions $[18,19]$.

To assess the situation in Estonia we aimed to study the pattern of healthcare visits and HIV testing 2 years before HIV diagnosis among people newly diagnosed with HIV in 2014-15.

\section{Methods}

This study is an observational retrospective study implementing secondary analysis of the data from the Estonian Health Insurance Fund (EHIF) and Health Board (HB). The sample consists of patients aged $\geq 16$ years who were diagnosed with HIV for the first time between 1 January 2014 and 31 December 2015.

\section{Data sources and definitions}

From the HB communicable diseases information system, we collected the following data for the people newly diagnosed with HIV in 2014-15: (i) date of HIV diagnosis (confirmation date in national HIV reference laboratory); (ii) sex and age at the time of HIV diagnosis; (iii) place of residence at the time of HIV diagnosis (on county level); (iv) self-reported transmission mode (heterosexual/MSM/injecting drug use/other/ unknown); (v) setting where HIV was diagnosed, categorised as one of the following: family practitioner (primary care); emergency medicine; infectious diseases clinics, including anonymous testing; gynaecology and obstetrics (including midwives); specialist doctors (all other specialist care); other (e.g. blood donors); prison; unknown.

Based on the unique national identification codes of the patients, HB data were linked with the data from EHIF's database of treatment invoices. EHIF is the core purchaser of healthcare services in Estonia, covering healthcare costs for insured people. EHIF also manages services for people without health insurance (covered directly from the state budget). EHIF database does not include prison health services and anonymous testing. After healthcare service provision, the provider sends an invoice to EHIF, which includes doctor and patient information (e.g. age, sex, diagnosis based on the World Health Organization (WHO) International Statistical Classification of Diseases and Related Health Problems (ICD-10) [20]) and services provided (tests performed, etc.). Every test in the database has a specific code. An HIV test has had a separate code since 2012.

For people diagnosed with HIV in 2014, we extracted invoices from the period 2012-14 and for those diagnosed in 2015, for 2013-15. For every person, we included invoices which started $\leq 730$ days (2 years) before HIV diagnosis (based on the start date of the invoice and the date of HIV diagnosis). We did not include invoices for which start/end date overlapped with HIV diagnosis date (assuming that the HIV test in these cases was the test leading to HIV diagnosis).

We did not include the invoices issued by the following specialties (as they either cannot order HIV tests or are not expected to do this): laboratory medicine, radiology, physiotherapy, ophthalmology, dentistry, medical genetics, psychology and nursing.

We used treatment invoices as a proxy for health care visits. The following data were extracted for every 
TABLE 1

Characteristics of HIV-infected patients, by year of HIV diagnosis, Estonia, 2014-2015 ( $\mathrm{n}=538)$

\begin{tabular}{|c|c|c|c|c|c|c|c|}
\hline \multirow{3}{*}{ Patient characteristics } & \multirow{2}{*}{\multicolumn{2}{|c|}{ Overall $(n=538)$}} & \multicolumn{4}{|c|}{ Year of HIV-infection diagnosis } & \multirow{3}{*}{$\mathrm{p}$ value } \\
\hline & & & \multicolumn{2}{|c|}{$2014(n=275)$} & \multicolumn{2}{|c|}{$2015(n=263)$} & \\
\hline & $\mathrm{n}$ & $\%$ & $\mathrm{n}$ & $\%$ & $\mathrm{n}$ & $\%$ & \\
\hline \multicolumn{8}{|l|}{ Age at HIV infection diagnosis (years) } \\
\hline Mean (median, SD, range) & \multicolumn{2}{|c|}{$\begin{array}{c}36.3 \\
(34 ; 10.7 ; 16-70)\end{array}$} & \multicolumn{2}{|c|}{$\begin{array}{c}36.6 \\
(34 ; 10.6 ; 19-70)\end{array}$} & \multicolumn{2}{|c|}{$\begin{array}{c}35.9 \\
(34 ; 10.8 ; 16-66)\end{array}$} & 0.5 \\
\hline \multicolumn{8}{|l|}{ Age group (years) } \\
\hline$<30$ & 167 & 31.0 & 81 & 29.5 & 86 & 32.7 & \multirow{3}{*}{0.5} \\
\hline $30-39$ & 197 & 36.6 & 99 & 36.0 & 98 & 37.3 & \\
\hline$>39$ & 174 & 32.4 & 95 & 34.5 & 79 & 30.0 & \\
\hline \multicolumn{8}{|l|}{ Sex } \\
\hline Male & 336 & 62.5 & 174 & 63.3 & 162 & 61.6 & \multirow{2}{*}{0.7} \\
\hline Female & 202 & 37.5 & 101 & 36.7 & 101 & 38.4 & \\
\hline \multicolumn{8}{|l|}{ Estonian region where HIV was diagnosed } \\
\hline Ida-Viru county & 228 & 42.4 & 119 & 43.3 & 109 & 41.4 & \multirow[b]{3}{*}{0.8} \\
\hline Harju county & 267 & 49.6 & 133 & 48.4 & 134 & 51.0 & \\
\hline Rest of Estonia & 43 & 8.0 & 23 & 8.3 & 20 & 7.6 & \\
\hline \multicolumn{8}{|l|}{ Setting of HIV diagnosis } \\
\hline Family practitioner & 41 & 7.6 & 20 & 7.3 & 21 & 8.0 & \multirow{8}{*}{$<0.001$} \\
\hline Emergency medicine & 21 & 3.9 & 9 & 3.3 & 12 & 4.5 & \\
\hline $\begin{array}{l}\text { Infectious diseases clinics, including } \\
\text { anonymous testing }\end{array}$ & 177 & 32.9 & 85 & 48.0 & 92 & 52.0 & \\
\hline Gynaecology and obstetrics & 50 & 9.3 & 22 & 8.0 & 28 & 10.6 & \\
\hline Specialist doctors & 132 & 24.5 & 69 & 25.1 & 63 & 24.0 & \\
\hline Other & 10 & 1.9 & 3 & 1.1 & 7 & 2.7 & \\
\hline Prison & 59 & 11.0 & 31 & 11.3 & 28 & 10.7 & \\
\hline Unknown & 48 & 8.9 & 36 & 13.1 & 12 & 4.5 & \\
\hline \multicolumn{8}{|l|}{ HIV transmission mode } \\
\hline Heterosexual & 302 & 56.1 & 160 & 58.2 & 142 & 54.0 & \multirow{4}{*}{0.005} \\
\hline MSM & 21 & 3.9 & 3 & 1.1 & 18 & 6.8 & \\
\hline Injecting drug use & 122 & 22.7 & 67 & 24.4 & 55 & 20.9 & \\
\hline Unknown & 93 & $17 \cdot 3$ & 45 & 16.3 & 48 & 18.3 & \\
\hline
\end{tabular}

MSM: men who have sex with men; SD: standard deviation.

invoice from EHIF's database: (i) invoice start and end dates which reflect the start and end for the health care services provided; (ii) insurance status (insured/ not insured); (iii) specialty of the doctor issuing the invoice; (iv) diagnoses (ICD-10 codes); (v) HIV testing (yes/no; if yes, then the date of testing).

The specialty of the doctor issuing the invoice was categorised as following: family practitioner (primary care); emergency medicine; infectious diseases; gynaecology and obstetrics (incl. midwives); dermatovenerology; psychiatry; specialist doctors (all other specialist care); general practitioners (unspecialised doctors working mostly in hospitals but also in primary care).

The diagnoses on treatment invoices were categorised as HIV ICs as recommended by the HIV in Europe
Initiative [8]: (i) cancers and neoplasms: C21, C34, C46, C53, C85-C89, C83, D15-D16, N87; (ii) infectious, fungal and parasitic diseases: A02.1, A15-A19, A31, A60, A81.2, A87.2-A87.9, B02, B15-B19, B25.9, B27, B55.0, A07.2, A07.3, B55, B57.2, B57.4, B58, B37, B39.0-B39.4, B45, B38.3-B38.9, B48.8; (iii) sexually

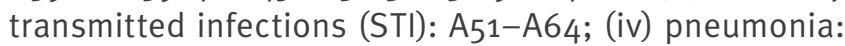
J13, J15-J16, J18; (v) diseases of the blood and bloodforming organs: D72.8; (vi) diseases of the skin and subcutaneous tissue: L21, L40; (vii) diseases of the genitourinary system: N15.9; (viii) diseases of the nervous system: G90.0, G35, G56, G57, G59, G61.0; (ix) diseases of the digestive system: K13.3; (x) symptoms: R50 (fever of unknown origin), R63.4 (abnormal weight loss), R59.1 (generalised enlarged lymph nodes). We also included the group F11 (opioid-related disorders). 


\begin{tabular}{|c|c|c|c|c|c|}
\hline \multirow{3}{*}{ Patient characteristics } & \multicolumn{4}{|c|}{ Treatment invoices } & \multirow{3}{*}{$\mathrm{p}$ value } \\
\hline & \multicolumn{2}{|c|}{$\begin{array}{c}\text { No } \\
(n=95)\end{array}$} & \multicolumn{2}{|c|}{$\begin{array}{c}Y^{a}{ }^{a} \\
(n=443)\end{array}$} & \\
\hline & $n$ & $\%$ & $\mathrm{n}$ & $\%$ & \\
\hline \multicolumn{6}{|l|}{ Sex } \\
\hline Male & 73 & 21.7 & 263 & 78.3 & \multirow{2}{*}{0.001} \\
\hline Female & 22 & 10.9 & 180 & 89.1 & \\
\hline \multicolumn{6}{|l|}{ Age group (years) } \\
\hline$<30$ & 14 & 8.4 & 153 & 91.6 & \multirow[b]{3}{*}{0.001} \\
\hline $30-39$ & 44 & 22.3 & 153 & 77.7 & \\
\hline$>39$ & 37 & 21.3 & 137 & 78.7 & \\
\hline \multicolumn{6}{|l|}{ Estonian region where HIV was diagnosed } \\
\hline Ida-Viru county & 38 & 16.7 & 190 & 83.3 & \multirow[b]{3}{*}{0.8} \\
\hline Harju county & 50 & 18.7 & 217 & 81.3 & \\
\hline Rest of Estonia & 7 & 16.3 & 36 & 83.7 & \\
\hline \multicolumn{6}{|l|}{ Setting of HIV diagnosis } \\
\hline Family practitioner & 3 & 7.3 & 38 & 92.7 & \multirow{8}{*}{0.003} \\
\hline Emergency medicine & 4 & 19.1 & 17 & 80.9 & \\
\hline Infectious diseases clinics, including anonymous testing & 38 & 21.5 & 139 & 78.5 & \\
\hline Gynaecology and obstetrics & 4 & 8.0 & 46 & 92.0 & \\
\hline Specialist doctors & 16 & 12.1 & 116 & 87.9 & \\
\hline Other & 1 & 10.0 & 9 & 90.0 & \\
\hline Prison & 20 & 33.9 & 39 & 66.1 & \\
\hline Unknown & 9 & 18.8 & 39 & 81.2 & \\
\hline \multicolumn{6}{|l|}{ HIV transmission mode } \\
\hline Heterosexual & 43 & 14.2 & 259 & 85.8 & \multirow{4}{*}{0.06} \\
\hline MSM & 3 & 14.3 & 18 & 85.7 & \\
\hline Injecting drug use & 25 & 20.5 & 97 & 79.5 & \\
\hline Unknown & 24 & 25.8 & 69 & 74.2 & \\
\hline
\end{tabular}

MSM: men who have sex with men.

a The target group.

We refer to people in our final sample who had EHIF treatment invoices within 2 years before HIV diagnosis as the target group. We refer to people who were 20-49 years old at the time of HIV diagnosis (which means they were at least 18 during the 2 years before HIV diagnosis) and were diagnosed in Harju or Ida-Viru County as the priority groups (their universal testing is recommended in Estonian guidelines for HIV testing [17]).

The term 'missed opportunity' has no consensus definition [21]. For the purpose of our study we defined missed opportunity as a healthcare visit during which an HIV test was not performed to a patient with an HIV IC or which occurred in Harju or Ida-Viru County among those aged 16-49 years. EHIF data do not include information on risk behaviours so we were not able to follow these indications.

\section{Statistical analysis}

The data were analysed using Microsoft Office Excel 2007 and Stata/IC 14.1. We used descriptive statistics to characterise participants and testing during healthcare visits. We compared categorical variables using the chi-squared or Fisher's exact tests with a significance level of less than 0.05 .

\section{Ethical statement}

The study protocol was approved by the Tallinn Medical Research Ethics Committee (decision number 1408) and the Estonian Data Protection Agency (decision number $2.2-1 / 16 / 7)$.

\section{Results}

Characteristics of the sample

A total of 561 new HIV cases were reported to the HB in 2014-15. We excluded 23 cases for the following reasons: no unique national identification code, younger 


\section{TABLE 3}

Characteristics of HIV-infected patients with treatment invoices within 2 years of HIV diagnosis by HIV testing, Estonia, 2014-2015 ( $\mathrm{n}=443)$

\begin{tabular}{|c|c|c|c|c|c|}
\hline \multirow[t]{2}{*}{ Patient characteristics } & \multicolumn{2}{|c|}{$\begin{array}{l}\text { Not tested } \\
(\mathrm{n}=371)\end{array}$} & \multicolumn{2}{|c|}{$\begin{array}{l}\text { Tested } \\
(n=72)\end{array}$} & \multirow[t]{2}{*}{ p value } \\
\hline & $\mathrm{n}$ & $\%$ & $\mathrm{n}$ & $\%$ & \\
\hline \multicolumn{6}{|l|}{ Sex } \\
\hline Male & 234 & 89.0 & 29 & 11.0 & \multirow{2}{*}{$<0.001$} \\
\hline Female & 137 & 76.1 & 43 & 23.9 & \\
\hline \multicolumn{6}{|l|}{ Age group (years) } \\
\hline$<30$ & 121 & 79.1 & 32 & 20.9 & \multirow[b]{3}{*}{0.05} \\
\hline $30-39$ & 127 & 83.0 & 26 & 17.0 & \\
\hline$>39$ & 123 & 89.8 & 14 & 10.2 & \\
\hline \multicolumn{6}{|c|}{ Estonian region where HIV was diagnosed } \\
\hline Ida-Viru county & 162 & 85.3 & 28 & $14 \cdot 7$ & \multirow[b]{3}{*}{0.7} \\
\hline Harju county & 178 & 82.0 & 39 & 18.0 & \\
\hline Rest of Estonia & 31 & 86.1 & 5 & 13.9 & \\
\hline \multicolumn{6}{|l|}{ HIV transmission mode } \\
\hline Heterosexual & 218 & 84.2 & 41 & 15.8 & \multirow[b]{4}{*}{0.9} \\
\hline MSM & 14 & 77.8 & 4 & 22.2 & \\
\hline Injecting drug use & 82 & 84.5 & 15 & 15.5 & \\
\hline Unknown & 57 & 82.6 & 12 & 17.4 & \\
\hline \multicolumn{6}{|l|}{ Year of HIV diagnosis } \\
\hline 2014 & 191 & 83.0 & 39 & 17.0 & \multirow{2}{*}{0.7} \\
\hline 2015 & 180 & 84.5 & 33 & 15.5 & \\
\hline
\end{tabular}

MSM: men who have sex with men.

than 16 years of age, previously diagnosed with HIV (Figure).

The final sample consisted of 538 adults with an average age of 36.3 years at the time of HIV diagnosis: $63 \%$ were men, $42 \%$ were diagnosed with HIV in IdaViru County and 50\% in Harju County. Of the 538, 56\% had been infected through heterosexual contact, $23 \%$ through injecting drug use, and $4 \%$ were MSM (Table 1).

Contact with the healthcare system during the 2 years before $\mathrm{HIV}$ diagnosis

The total number of invoices was 4,046. The average number of invoices per person in the final sample $(n=538)$ was 7.5 (median: 6; range: $0-68$ ). Almost three quarters of those in the final sample $(71 \%)$ had visited a family practitioner at least once $(n=383)$.

Of the final sample, 443 (82\%) had EHIF treatment invoices within 2 years before HIV diagnosis (the target group), with an average of 9.1 invoices per person (median: 7; range: $1-68)$. Of the target group, 331 (75\%) had invoices from family practitioners and specialist doctors, 56 (13\%) from specialist doctors only, and 52 (12\%) from family practitioners only. Four people (1\%) had only emergency medicine invoices.
Women were more likely to have visited healthcare services than men, people younger than 39 years of age more so than older ones. People diagnosed with HIV in prisons had had fewer healthcare encounters in civil system (Table 2$)$. Of all women $(n=202), 55 \%$ had visited a gynaecologist or a midwife at least once within 2 years before their HIV diagnosis ( $18 \%$ of all healthcare visits among women involved in the study).

\section{HIV testing during the 2 years before HIV diagnosis}

Out of the people in the target group, 72 (16\%; $13 \%$ of the final sample) had been tested for HIV during the 2 years preceding HIV diagnosis. Women had been tested more often than men ( $24 \%$ vs $11 \%$ ) and younger age groups more than older age groups (Table 3 ). Of the 72 people in the target group, 46 had been tested once, and 26 had been tested twice or more. The mean time from the last HIV test to HIV diagnosis was 408 days (median: 411 days; range: 21-721 days). Sixteen people had their previous HIV test within 6 months of HIV diagnosis and 32 within 1 year of HIV diagnosis.

The specialties with the largest number of visitors tested (data not shown in tables) were infectious diseases (12 people out of 25 tested at least once; $48 \%$ of those who had visited this specialty), and gynaecology and obstetrics ( 31 people out of 112 tested at least once; $28 \%$ of those who had visited this specialty). The lowest percentage of tested patients was in primary care (13 people out of $383 ; 3 \%$ of those who had visited this specialty).

\section{HIV testing in patients with HIV indicator conditions}

Of the target group, 137 patients (31\%) had at least one ICD-10 code for HIV IC on at least one of their treatment invoices. People who had an IC on at least one invoice did not differ from those who had none by age, sex and HIV transmission group ( $p>0.5$ ). Fewer people had ICs in Ida-Viru (46/190; $24 \%$; $p=0.04$ ) compared with Harju County $(78 / 217 ; 35 \%)$ and the rest of Estonia (12/36; 33\%).

Of the 137,12 people ( $9 \%$ ) had been HIV tested at least once when they had an IC. Some people had several treatment invoices (proxy for healthcare visit) and different ICs. Altogether, in 390 cases the treatment invoice included ICD-10 code(s) for HIV ICs (Table 4). Of these, $5 \%(n=20)$ included an HIV test. The largest number of invoices with ICs was from family practitioners $(n=202)$; out of these only one included an HIV test (Table 4). Most common ICs were certain infectious diseases and opioid use (Table 5).

\section{HIV testing in patients belonging to the priority group}

Of the target group, 356 (80\%) were 20-49 years old at the time of the HIV diagnosis and were diagnosed in Harju or Ida-Viru County. These factors placed them in the priority groups set in the Estonian guidelines for HIV testing. Their average number of treatment invoices 
Treatment invoices $(\mathrm{n}=4,046)$ according to HIV indicator conditions and HIV testing by setting, patients diagnosed with HIV, Estonia, 2014-2015 ( $\mathrm{n}=434)$

\begin{tabular}{|c|c|c|c|c|c|c|c|}
\hline \multirow{3}{*}{ Setting } & \multicolumn{3}{|c|}{$\begin{array}{c}\text { Treatment invoices with HIV indicator } \\
\text { conditions }\end{array}$} & \multicolumn{3}{|c|}{$\begin{array}{l}\text { Treatment invoices with no HIV indicator } \\
\text { conditions }\end{array}$} & \multirow{3}{*}{$\mathrm{p}$ value } \\
\hline & \multirow{2}{*}{$\begin{array}{c}\text { Total } \\
\mathrm{n}\end{array}$} & \multicolumn{2}{|c|}{ With HIV test } & \multirow{2}{*}{$\begin{array}{c}\text { Total } \\
\mathrm{n}\end{array}$} & \multicolumn{2}{|c|}{ With HIV test } & \\
\hline & & $n$ & $\%$ & & $n$ & $\%$ & \\
\hline Family practitioners & 202 & 1 & 0.5 & 1,822 & 13 & 0.7 & 0.7 \\
\hline Emergency medicine & 12 & 1 & 8.3 & 92 & 7 & 7.6 & 0.9 \\
\hline Infectious diseases & 18 & 10 & 55.6 & 20 & 7 & 35.0 & 0.2 \\
\hline Dermatovenerology & 32 & 1 & 3.1 & 110 & 3 & 2.7 & 0.9 \\
\hline Psychiatry & 29 & 2 & 6.9 & 213 & 1 & 0.5 & 0.003 \\
\hline Gynaecology and obstetrics & 39 & 2 & 5.1 & 353 & 41 & 11.6 & 0.2 \\
\hline Other specialist doctors & 46 & 1 & 2.2 & 791 & 10 & 1.3 & 0.6 \\
\hline General practitionersa & 12 & 2 & 16.7 & 255 & 11 & $4 \cdot 3$ & 0.05 \\
\hline Total & 390 & 20 & 5.1 & 3,656 & 93 & 2.5 & 0.003 \\
\hline
\end{tabular}

a The specialty of the doctor issuing the invoice was categorised differently to the settings where HIV was diagnosed (see methodology).

was 8.9 (median: 7; range: $1-68$ ). Of these 356, 304 $(85 \%)$ had visited family practitioner at least once. The total number of family practitioner visits was 1,577 and during these visits, HIV tests were performed only 13 times (0.8\%).

Of those in the priority groups, 65 (18\%) had been tested for HIV at least once. They were more likely to have been tested than those over 49 years of age or from other regions of Estonia $(8 \% ; p=0.02)$. They had an HIV IC on their treatment invoice as often as others ( $31 \%$ vs $31 \% ; p=0.9$ ). Those with an HIV IC were tested more often than people with ICs who did not belong to the priority group ( $29 \%$ vs $13 \% ; p=0.1$ ).

\section{Discussion}

Increased HIV-related morbidity and mortality, poorer response to treatment and increased healthcare costs are the consequences of late HIV diagnosis. Moreover, delayed diagnosis is one of the most important determinants of increased rates of HIV transmission [22]. Our data confirms that many HIV-infected patients in Estonia make numerous visits to healthcare services before being tested. In our study, $82 \%$ of the new HIV cases had visited healthcare services at least once in the 2 years before HIV diagnosis and the mean number of their visits was 9.1. We found evidence of HIV testing for $16 \%$ of them. Only $13 \%$ of all new HIV cases had been tested in a healthcare setting. Thus, missed opportunities for testing in healthcare contribute to the late diagnosis of HIV in Estonia.

Of all new HIV cases, $72 \%$ had visited a family practitioner at least once but only $3 \%$ of them had been tested for HIV at least once. Also, less than $1 \%$ of the visits from people belonging to HIV testing priority groups resulted in HIV testing at family medicine practices. This is an extremely low level of testing.
Considering that primary care is the most-visited setting, testing should be scaled up by ensuring proper funding for family practitioners to test everyone in need, including people with no health insurance, and possibly also introducing incentives for healthcare personnel to encourage testing.

In our study, $95 \%$ of cases with ICs were not tested for HIV. Even in medical professions like dermatovenerology, only $3 \%$ of patients with ICs were tested for HIV. This has also been seen in other countries. In the United States, in New York City, many patients being evaluated for gonorrhoea and chlamydia failed to receive HIV testing, especially in emergency and inpatient settings. The testing rates were, however, much higher than in our study (in $2015,70 \%$ of men and $51 \%$ of women received same-day HIV testing) [23]. In the Netherlands, a study among PLHIV revealed that in one third of the STI-related consultations for persons from high-risk groups, no HIV test was performed in primary care [7].

Also, of all new cases aged 20-49 years from high incidence regions, $82 \%$ had not been tested for HIV despite being in the priority group. HIV testing among them was mostly related to women being tested in gynaecology and obstetrics (opt-out testing twice during pregnancy is recommended by law). This low level of testing suggests that adherence to the Estonian HIV testing guidance is very low in recommended populations, conditions and settings.

Two thirds of our patients had no record of HIV ICs in the 2 years before HIV diagnosis. This has also been seen in other settings suggesting that symptomatology is not a reliable criterion to prompt HIV testing [24] and that routine testing is needed before patients present to care with symptoms suggestive of HIV [25]. 
Treatment invoices with HIV indicator conditions among people diagnosed with HIV ${ }^{\text {a }}$ within 2 years of HIV diagnosis, Estonia, 2014-2015 $(\mathrm{n}=434)$

\begin{tabular}{|l|c|c|c|c|}
\hline \multirow{2}{*}{ HIV indicator condition group } & \multicolumn{2}{|c|}{ All invoices with ICs } & \multicolumn{2}{|c|}{ Invoices with ICs with HIV tests } \\
\cline { 2 - 5 } & $n$ & $\begin{array}{c}\text { Proportion of all } \\
\text { invoices }\end{array}$ & $\mathrm{n}$ & $\begin{array}{c}\text { Proportion of all invoices with respective } \\
\text { ICs \% }\end{array}$ \\
\hline Certain infectious, fungal and parasitic diseases & 165 & 4.1 & 14 & 8.5 \\
\hline Pneumonia & 24 & 0.6 & 0 & 0 \\
\hline HIV-related symptoms & 16 & 0.4 & 1 & 6.3 \\
\hline Sexually transmitted infections & 21 & 0.5 & 2 & 9.5 \\
\hline Cancers and neoplasms & 2 & 0.05 & 1 & 50.0 \\
\hline Diseases of the skin & 46 & 1.1 & 1 & 2.2 \\
\hline Diseases of the nervous system & 15 & 0.4 & 0 & 0 \\
\hline $\begin{array}{l}\text { Mental and behavioural disorders due to use of } \\
\text { opioids }\end{array}$ & 110 & 2.7 & 1 & $\mathbf{2 0}$ \\
\hline Total & $\mathbf{3 9 0 ^ { \mathrm { b } }}$ & $\mathbf{9 . 6}$ & $\mathbf{2 0}$ & 0.9 \\
\hline
\end{tabular}

IC: indicator condition.

a Total number of invoices $n=4,046$.

b 381 invoices had one indicator condition (IC) and nine invoices had two IC ICD-10 codes.

Of the newly diagnosed HIV cases, $18 \%$ had no evidence of contact with healthcare services before HIV diagnosis (the proportion was higher among men and people aged $\geq 30$ years, and those diagnosed with HIV in prisons). This does not necessarily mean that they had not been tested in the previous 2 years. In Estonia, it is also possible to test anonymously, which is not reflected in the EHIF's database. People diagnosed in prisons had fewer healthcare visits. One reason is incarceration itself (they were in prison for at least part of the 2 years before HIV diagnosis), another reason may be that incarcerated people are likely to belong to more vulnerable population groups with fewer healthcare encounters in general. In Estonian prisons, HIV testing is offered routinely upon and during imprisonment [16], resulting in their diagnosis in the prison setting.

Different definitions of 'missed opportunity' have been used by different authors, usually reflecting local HIV testing guidance. Also, the timespan under evaluation has been different, most often being 1 [4,6,26,27], 3 $[5,24]$, or 5 years before HIV diagnosis [21,25]. As a result, the proportions of missed opportunities for HIV testing in the medical literature range from $15 \%$ to $80 \%$. We chose a 2 -year period, because HIV testing could be tracked in EHIF database since 2012. Unlike some other studies $[21,25]$, we were not able to track the need for testing based on risk behaviours. For example, a Swiss study revealed that $59 \%$ of missed opportunities were in people at epidemiological risk of acquiring HIV (belonging to or having a sexual partner from a high-risk group) [21]. Thus, the missed opportunities in our study may be underestimated.

\section{Limitations}

Our data has several limitations. The EHIF database's primary function is to track healthcare costs and not necessarily to provide information on the quality of healthcare. ICS as well as HIV tests may have been miscoded on treatment invoices. HIV tests can be marked on the invoice not only as 'HIV test' but also as 'detection of infection marker using immunological methods'. The price for these two tests has always been the same, thus for tracking of healthcare costs it has not been important to distinguish which one is marked on the invoice. This misclassification would tend to increase rather than decrease the proportion tested.

We have no information about the HIV test offer and thus the proportion refusing testing. In Estonia, the only group tested mandatorily are blood and organ donors [11]. There is no information on refusal rates in any setting.

We have no data on private healthcare services (paid by patients themselves or by other insurance companies) and HIV testing therein. Considering that $94 \%$ of the population has national health insurance $(87 \%$ of 20-49-year-olds), the proportion of these services is small. We also have no data on testing of these patients in prisons as well as anonymous testing sites. A relatively large proportion of new HIV cases diagnosed in the past decade have been found in both these settings $[11,15]$.

\section{Conclusions}

Missed opportunities for HIV testing among newly diagnosed HIV cases were numerous in Estonia. Therefore, it is critical to follow Estonian HIV testing guidelines, 
paying special attention to testing men aged 16-49 years and living in high-incidence areas. Primary care had been visited by almost three quarters of patients but testing rates there were extremely low; this is one of the most important settings in which to promote testing. While almost one fifth of our sample had no healthcare encounters before HIV diagnosis, offering testing in alternative settings (community-based organisations, etc.) is also needed. Considering the limitations, we recommend a clinical audit based on patient records in order to evaluate the implementation of the HIV testing guidance.

\section{Acknowledgements}

The authors would like to thank Lauren Nicolas Combs for constructive comments and for editing the manuscript.

This study was financed by the National Institute for Health Development, Estonia, from project OptTEST (Optimising testing and linkage to care for HIV across Europe; 20142017) (grant no. 20131102) of the European Commission and Estonian Ministry of Education and Science Project IUT 42-2.

This publication arises from the OptTEST project, which received funding from the second European Union Health Programme (2008-2013). The content of this publication represents the views of the authors and is their sole responsibility; it can in no way be taken to reflect the views of the European Commission and/or the Executive Agency for Health and Consumers or any other body of the European Union. The European Commission and/or the Executive Agency do(es) not accept responsibility for any use that may be made of the information it contains.

\section{Conflict of interest}

None declared.

\section{Authors' contributions}

KR designed the study. KR, SL and JE performed the data analysis. KR, LL, SL and JE contributed to interpreting the results. KR drafted the manuscript and LL, SL and JE contributed to writing it. All authors approved the final version of the manuscript.

\section{References}

1. World Health Organization (WHO). Consolidated guidelines on HIV testing services. Geneva: WHO; 2015. Available from: https://www.who.int/hiv/pub/guidelines/hiv-testing-services/ en/

2. Gourlay A, Noori T, Pharris A, Axelsson M, Costagliola D, Cowan S, et al. The Human Immunodeficiency Virus continuum of care in European Union countries in 2013: Data and challenges. Clin Infect Dis. 2017;64(12):1644-56. https://doi. org/10.1093/cid/cix212 PMID: 28369283

3. Pharris A, Quinten C, Noori T, Amato-Gauci AJ, van Sighem $A$, Surveillance EHA, et al. Estimating HIV incidence and number of undiagnosed individuals living with HIV in the European Union/European Economic Area, 2015. Euro Surveill. 2016;21(48):30417. https://doi.org/10.2807/1560-7917. ES.2016.21.48.30417 PMID: 27934585

4. Lyons MS, Lindsell CJ, Wayne DB, Ruffner AH, Hart KW, Fichtenbaum CJ, et al. Comparison of missed opportunities for earlier HIV diagnosis in 3 geographically proximate emergency departments. Ann Emerg Med. 2011;58(1) Suppl 1;S17-22.e1,
S22.e1. https://doi.org/10.1016/j.annemergmed.2011.03.018 PMID: 21684399

5. Champenois K, Cousien A, Cuzin L, Le Vu S, Deuffic-Burban S, Lanoy $\mathrm{E}$, et al. Missed opportunities for HIV testing in newlyHIV-diagnosed patients, a cross sectional study. BMC Infect Dis. 2013;13(1):200. https://doi.org/10.1186/1471-2334-13-200 PMID: 23638870

6. Burns FM, Johnson AM, Nazroo J, Ainsworth J, Anderson J, Fakoya A, et al. Missed opportunities for earlier HIV diagnosis within primary and secondary healthcare settings in the UK. AIDS. 2008;22(1):115-22. https://doi.org/10.1097/ QAD.ob013e3282f1d4b6 PMID: 18090399

7. Joore IK, Arts DL, Kruijer MJ, Moll van Charante EP, Geerlings SE, Prins JM, et al. HIV indicator condition-guided testing to reduce the number of undiagnosed patients and prevent late presentation in a high-prevalence area: a case-control study in primary care. Sex Transm Infect. 2015;91(7):467-72. https:// doi.org/10.1136/sextrans-2015-052073 PMID: 26126531

8. HiE. HIV Indicator Conditions: Guidance for Implementing HIV Testing in Adults in Health Care Settings. Copenhagen: Copenhagen University; 2012. Available from: http:// hiveurope.eu/Portals/o/Guidance.pdf.pdf

9. Statistics Estonia. Population statistics. Tallinn: Statistics Estonia; 2017. [Accessed 17 Jun 2018]. Available from: https:// www.stat.ee/stat-population-at-beginning-of-year

10. European Centre for Disease Prevention and Control (ECDC), World Health Organization (WHO) Regional Office for Europe. HIV/AIDS surveillance in Europe 2018-2017 data. Copenhagen: WHO Regional Office for Europe; 2018. Available from: https:// ecdc.europa.eu/sites/portal/files/documents/hiv-aidssurveillance-europe-2018.pdf

11. National Institute for Health Development (NIHD). HIV in Estonia. Narrative report for Global AIDS Monitoring 2017 Tallinn: NIHD; 2017. Available from: http://www.tai.ee/et/ terviseandmed/uuringud/download/413

12. Laisaar KT, Raag M, Lutsar I, Uusküla A. People living with HIV in Estonia: engagement in HIV care in 2013. Euro Surveill. 2016;21(43):30380. https://doi.org/10.2807/1560-7917. ES.2016.21.43.30380 PMID: 27813471

13. Rüütel K, Kaur E, Epštein J. HIV nakkuse ja kaasuvate infektsioonide epidemioloogiline olukord Eestis, 2000-2017. [Epidemiology of HIV and associated infections in Estonia, 2000-2017]. Tallinn: National Institute for Health Development, Health Board; 2017. Estonian. Available from: http://www.tai. ee/et/terviseandmed/uuringud/download/445

14. Soodla P, Rajasaar H, Avi R, Zilmer K, Kink K, Novikova L, et al. Design and structure of the Estonian HIV Cohort Study (E-HIV). Infect Dis (Lond). 2015;47(11):768-75. https://doi.org/10.3109/ 23744235.2015.1061203 PMID: 26153824

15. Rüütel K, Kallavus K, Tomera I. OptTEST by HiE. Monitoring anonymous HIV testing in Estonia from 2005 to 2015. HIV Med. 2018;19(Suppl 1):16-20. https://doi.org/10.1111/hiv.12587 PMID: 29488697

16. Kivimets K, Uuskula A. HIV testing and counselling in Estonian prisons, 2012 to 2013: aims, processes and impacts. Euro Surveill. 2014;19(47):20970. https://doi.org/10.2807/156o7917.ES2014.19.47.20970 PMID: 25443037

17. Ministry of Social Affairs. HIV-nakkuse testimise ja HIVpositiivsete isikute ravile suunamise tegevusjuhis. [Guidelines for HIV testing and referral to care for people with HIV]. Tallinn: Ministry of Social Affairs; 2012. Estonian. Available from: http://www.esid.ee/cms/tl_files/failid/failid/HIV_testimise_ ja ravile suunamise uuendatud juhis 31.pdf

18. Rüütel K, Lemsalu L, Lätt S. OptTEST by HiE. Monitoring HIV indicator condition guided HIV testing in Estonia. HIV Med. 2018;19(Suppl 1):47-51. https://doi.org/10.1111/hiv.12586 PMID: 29488700

19. Rüütel K, Lemsalu L. Monitoring HIV testing guidance implementation in Estonia. HepHIV 2017 Conference: HIV and Viral Hepatitis: Challenges of Timely Testing and Care Malta 2017.

20. World Health Organization (WHO). International Statistical Classification of Diseases and Related Health Problems. 10th Revision (ICD-10). Geneva: WHO. [Accessed 17 Mar 2018]. Available from: http://www.who.int/classifications/icd/ ICD10Volume2 en 2010.pdf

21. Lhopitallier L, Moulin E, Hugli O, Cavassini M, Darling KEA. Missed opportunities for HIV testing among patients newly presenting for HIV care at a Swiss university hospital: a retrospective analysis. BMJ Open. 2018;8(6):e019806. https:// doi.org/10.1136/bmjopen-2017-019806 PMID: 29895647

22. Blasi F, Matteelli A. Indicator condition-guided HIV testing in Europe: a step forward to HIV control. Eur Respir J. 2013;42(3):572-5. https://doi.org/10.1183/09031936.00179412 PMID: 24000248 
23. Kapadia SN, Singh HK, Jones S, Merrick S, Vaamonde CM. Missed opportunities for HIV testing of patients tested for sexually transmitted infections at a large urban health care system from 2010 to 2015. Open Forum Infect Dis. 2018;5(7):ofy165. https://doi.org/10.1093/ofid/ofy165 PMID: 30087904

24. Liggett A, Futterman D, Umanski GI, Selwyn PA. Missing the mark: ongoing missed opportunities for HIV diagnosis at an urban medical center despite universal screening recommendations. Fam Pract. 2016;33(6):644-8. https://doi. org/10.1093/fampra/cmw075 PMID: 27507566

25. Inghels M, Niangoran S, Minga A, Yoboue JM, Dohoun L, Yao $A$, et al. Missed opportunities for HIV testing among newly diagnosed HIV-infected adults in Abidjan, Côte d'Ivoire. PLoS One. 2017;12(10):e0185117. https://doi.org/10.1371/journal. pone.0185117 PMID: 28977006

26. Gullón A, Verdejo J, de Miguel R, Gómez A, Sanz J. Factors associated with late diagnosis of HIV infection and missed opportunities for earlier testing. AIDS Care. 2016;28(10):1296 300. https://doi.org/10.1080/09540121.2016.1178700 PMID: 27144427

27. Zucker J, Patterson B, Ellman T, Slowikowski J, Olender S, Gordon P, et al. Missed opportunities for engagement in the prevenion continuum in a predominantly black and latino community in New York City. AIDS Patient Care STDS. 2018;32(11):432-7. https://doi.org/10.1089/apc.2018.0127 PMID: 30398951

\section{License, supplementary material and copyright}

This is an open-access article distributed under the terms of the Creative Commons Attribution (CC BY 4.0) Licence. You may share and adapt the material, but must give appropriate credit to the source, provide a link to the licence and indicate if changes were made.

Any supplementary material referenced in the article can be found in the online version.

This article is copyright of the authors or their affiliated institutions, 2019. 